\section{Fluorescence and electron microscopy to visualize the intracellular fate of nanoparticles for drug delivery}

\author{
M. Costanzo, ${ }^{1}$ F. Carton, ${ }^{1}$ A. Marengo, ${ }^{2}$ \\ G. Berlier, ${ }^{3}$ B. Stella, ${ }^{2}$ S. Arpicco, ${ }^{2}$ \\ M. Malatesta ${ }^{1}$ \\ 'Department of Neurosciences, \\ Biomedicine and Movement Sciences, \\ Anatomy and Histology Section, \\ University of Verona \\ 2Department of Drug Science and \\ Technology, University of Turin \\ ${ }^{3}$ Department of Chemistry and NIS \\ Research Centre, University of Turin, \\ Italy
}

\section{Abstract}

In order to design valid protocols for drug release via nanocarriers, it is essential to know the mechanisms of cell internalization, the interactions with organelles, and the intracellular permanence and degradation of nanoparticles (NPs) as well as the possible cell alteration or damage induced. In the present study, the intracellular fate of liposomes, polymeric NPs and mesoporous silica NPs (MSN) has been investigated in an in vitro cell system by fluorescence and transmission electron microscopy. The tested nanocarriers proved to be characterized by specific interactions with the cell: liposomes enter the cells probably by fusion with the plasma membrane and undergo rapid cytoplasmic degradation; polymeric NPs are internalized by endocytosis, occur in the cytoplasm both enclosed in endosomes and free in the cytosol, and then undergo massive degradation by lysosome action; MSN are internalized by both endocytosis and phagocytosis, and persist in the cytoplasm enclosed in vacuoles. No one of the tested nanocarriers was found to enter the nucleus. The exposure to the different nanocarriers did not increase cell death; only liposomes induced a reduction of cell population after long incubation times, probably due to cell overloading. No subcellular damage was observed to be induced by polymeric NPs and MSN, whereas transmission electron microscopy revealed cytoplasm alterations in liposome-treated cells. This important information on the structural and functional relationships between nanocarriers designed for drug delivery and cultured cells further proves the crucial role of microscopy techniques in nanotechnology.

\section{Introduction}

Nanomedicine bears nanotechnology and medicine together, with the aim to obtain new therapeutic approaches and improve current treatments. ${ }^{1}$ The unique features of nanomaterials, such as e.g., increased surface area and quantum effects, are responsible for their remarkable efficacy in establishing molecular interactions at the cellular and subcellular level. Due to these peculiarities, nanocarriers received special attention in recent years, as suitable tools for efficiently delivering drugs or diagnostic agents to the target sites. Nanoparticles (NPs) may be loaded with relatively large variety of drug molecules (e.g., small molecules, peptides, nucleic acids) which are protected from cleavage by external agents, and the encapsulated drugs do not participate in the control over pharmacokinetic and biodistribution. Thus, NP-based targeted therapy has emerged as a unique strategy to maintain a drug therapeutic dose at the target site, while reducing systemic drug toxicity and adverse side effects to healthy tissues.,3

A plethora of nanosized drug-delivery systems has been developed, and particular attention has been paid to liposomes and biodegradable polymeric NPs, as biocompatible and versatile systems to encapsulate active agents.

Liposomes are nanoconstructs made of natural or synthetic phospholipids surrounding a water core. Liposomes spontaneously form when phospholipids are dispersed in water, and are non-toxic, biodegradable, and biocompatible, being phospholipids their major component. A wide variety of drugs may be encapsulated in liposomes into either the aqueous core or the surrounding bilayer., ${ }^{4,5}$ Liposomes, especially the cationic ones, are also used for gene therapy, and are considered the most suitable transfecting vectors among the currently used synthetic (non-viral) carriers. ${ }^{6-10}$

Polymeric NPs include nanospheres and nanocapsules composed of natural or synthetic polymers, in which drugs can be adsorbed, dissolved, entrapped or encapsulated. Nanospheres are matrix systems where the loaded drug is uniformly dispersed, while in nanocapsules the drug is confined to the inner aqueous or oily cavity surrounded by a tiny polymeric membrane. ${ }^{11}$ Polymeric NPs have good encapsulation efficiency and high stability in plasma, and increase the solubility and stability of hydrophobic drugs while lowering their toxicity, thus permitting a controlled release at the target site at relatively low doses. ${ }^{12-15}$

Mesoporous silica NPs (MSN) have recently attracted attention as promising components of multimodal NP systems, owing to their straightforward synthesis and functionaliza-
Correspondence: Manuela Malatesta

Department of Neurosciences, Biomedicine and Movement Sciences, Anatomy and Histology Section, University of Verona, Strada Le Grazie 8 , 37134 Verona, Italy.

Tel. +39.045.8027155 - Fax: 39.045.8027163.

E-mail: manuela.malatesta@univr.it

Key words: Liposomes; mesoporous silica nanoparticles; polymeric nanoparticles; fluorescence microscopy; electron microscopy.

Acknowledgments: we thank Dr. Federico Boschi for skillful assistance in confocal fluorescence analysis. M.C. and F.C. are PhD students in receipt of a fellowship from Doctoral Programs of the University of Verona. This work was supported by MIUR - University of Turin Fondi Ricerca Locale (ex-60\%).

Received for publication: 1 March 2016. Accepted for publication: 4 April 2016.

This work is licensed under a Creative Commons Attribution-NonCommercial 4.0 International License (CC BY-NC 4.0).

(C) Copyright M. Costanzo et al., 2016 Licensee PAGEPress, Italy

European Journal of Histochemistry 2016; 60:2640 doi:10.4081/ejh.2016.2640

tion, tunable pore size, large drug loading capacity, good chemical stability, and adequate biocompatibility. ${ }^{16,17}$ MSN can encapsulate both small molecules and oligonucleotides. ${ }^{18}$

Despite the numerous studies on the physicochemical and pharmacological properties of liposomes, polymeric NPs and MSN, little attention has so far been paid to investigate the mechanisms of cell internalization, organelle interactions, and intracellular permanence and degradation as well as the possible NP-related cell alteration or damage. This information is essential for designing suitable protocols for NP-mediated drug delivery, ${ }^{19-21}$ and in the present study the intracellular fate of liposomes, polymeric NPs and MSN has been investigated in an in vitro cell system by fluorescence and transmission electron microscopy.

\section{Materials and Methods}

\section{Preparation and characterization of NPs}

Fluorescent labelled liposomes were prepared by thin lipid film hydration and extrusion method. Briefly, a chloroform solution of the lipid components (Avanti Polar-Lipids distributed by Spectra 2000 Rome, Italy) 1,2dipalmitoyl-sn-glycero-3-phosphocholine (DPPC), cholesterol (Chol), and L- $\alpha$ phosphatidyl-DL-glycerol sodium salt (PG) (70:30:3 
molar ratios) was evaporated and the resulting lipid film was dried under vacuum overnight. Lipid films were hydrated with a $10 \mathrm{mM}$ solution of fluorescein-5-(and-6)-sulfonic acid trisodium salt (Invitrogen, Life Technologies, Monza, Italy) in HEPES [4-(2-hydroxyethyl) piperazine-1-ethanesulforic acid] buffer (pH 7.4), and the suspension was vortex mixed for $10 \mathrm{~min}$ and bath sonicated. The formulations were extruded (Extruder, Lipex, Vancouver, Canada) at $60^{\circ} \mathrm{C}$ passing the suspension 10 times under nitrogen through $220 \mathrm{~nm}$ polycarbonate membrane (Costar, Corning Incorporated, NY). To prepare hyaluronated liposomes, $\mathrm{HA}_{17000}$-DPPE conjugate was previously prepared as reported by Arpicco et al. ${ }^{4}$ The lipid films were made up of DPPC/Chol (70:30 molar ratio) and then hydrated using a solution of $\mathrm{HA}_{17000}$-DPPE conjugate ( 3 molar ratio) in HEPES.

Fluorescent labelled polymeric nanoparticles were prepared by nanoprecipitation of the copolymer poly(methoxypolyethyleneglycol cyanoacrylate-co-hexadecyl cyanoacrylate) (poly(MePEGCA-co-HDCA)) obtained as earlier reported ${ }^{22}$. Practically, $12 \mathrm{mg}$ of the copolymer and $16.8 \mu \mathrm{g}$ of Nile red ((9-diethylamino$5 H$-benzo $[\alpha]$ phenoxazine-5-one), SigmaAldrich, Milan, Italy) were dissolved in $2 \mathrm{~mL}$ of warm acetone; this solution was then added to $4 \mathrm{ml}$ of MilliQ ${ }^{\circledR}$ water under magnetic stirring. Precipitation of nanoparticles occurred spontaneously. After solvent evaporation under reduced pressure, an aqueous suspension of fluorescent nanoparticles was obtained. ${ }^{23}$ Fluorescent liposomes and polymeric NPs were purified from non-incorporated dye by gel filtration on a Sepharose CL-4B column.

The mean particle size and the polydispersity index (PI) of liposomes and polymeric nanoparticles were determined at $25^{\circ} \mathrm{C}$ by quasi-elastic light scattering (QELS) using a nanosizer (Nanosizer Nano Z, Malvern Inst., Malvern, UK). The selected angle was $173^{\circ}$ and the measurement was made after dilution of the nanoparticle suspension in MilliQ ${ }^{\circledR}$ water. Each measure was performed in triplicate.

Amino-mesoporous silica NPs $\left(\mathrm{NH}_{2}-\mathrm{MSN}\right)$ were prepared by using cetyltrimethylammonium bromide (CTAB) as structure directing agent (SDA) as previously described. ${ }^{17}$ Fluorescein isothiocyanate (FITC) labelled MSN were prepared as reported by ${ }^{24}$ with minor modifications. Briefly, at a suspension of $1 \mathrm{mg}$ of $\mathrm{NH}_{2}$-MSN in $150 \mu \mathrm{L}$ of MilliQ ${ }^{\circledR}$ water $250 \mu \mathrm{L}$ of FITC ethanol solution $(0.3 \mathrm{mg} / \mathrm{mL})$ were added. The mixture was maintained for 5 $\mathrm{h}$ under stirring in the dark and then the nanoparticles were centrifuged and washed with ethanol three times until the supernatants were colorless.

The particle surface charge of all formulations was investigated by zeta potential meas- urements at $25^{\circ} \mathrm{C}$ applying the Smoluchowski equation and using the Nanosizer Nano Z. Measurements were carried out in triplicate.

\section{In vitro cell culture}

HeLa cells, a human cell line commonly used for basic research as a standardised in vitro system, were grown in Dulbecco's modified Eagle medium supplemented with $10 \%$ $(\mathrm{v} / \mathrm{v})$ fetal calf serum, 1\% (w/v) glutamine, $10,000 \mathrm{units} / \mathrm{mL}$ of penicillin and $10,000 \mu \mathrm{g} / \mathrm{mL}$ of streptomycin (Gibco by Life Technologies, Milan, Italy), at $37^{\circ} \mathrm{C}$ in a $5 \% \mathrm{CO}_{2}$ humidified atmosphere. Cells were trypsinized (0.25\% trypsin in PBS containing 0.05\% EDTA) when sub-confluent, and seeded either on 12 multiwell plastic microplates $\left(2 \times 10^{4}\right.$ per well $)$ for cell viability evaluation or glass coverslips in 12 -multi-well plastic microplates $\left(1 \times 10^{4}\right.$ per well) for fluorescence and transmission electron microscopy (TEM). One day after seeding, the initial medium was replaced with a fresh one containing fluorescent NP suspensions: both uncoated and hyaluronic acid-coated liposomes were administered at the concentration of $500 \mu \mathrm{g} / \mathrm{mL}, \mathrm{MSN}$ at $50 \mu \mathrm{g} / \mathrm{mL}$ and polymeric NPs at $100 \mu \mathrm{g} / \mathrm{ml}$. The chosen NP concentrations were previously demonstrated to be noncytotoxic for various cultured cells. ${ }^{4,14,25}$ Cells were incubated with NPs for $2 \mathrm{~h}, 24 \mathrm{~h}$ and $48 \mathrm{~h}$ and then processed as described below; in parallel, untreated cells were used as control. HeLa are highly proliferating cells with a cell cycle of about $20 \mathrm{~h},{ }^{26}$ therefore a $48 \mathrm{~h}$ incubation time allows the completion of two cycles.

\section{Cell viability assay}

To estimate the effect of NPs on cell viability, HeLa cultures at all the incubation times were detached by mild trypsinization and stained in suspension for 2 min with $0.01 \%$ Trypan blue in the culture medium: cells that were permeable to Trypan blue were considered as non-viable and their percentage was estimated by microscope counting on a Burker hemocytometer; cell samples not exposed to NPs were considered as controls. Results were expressed as the mean \pm standard error (SE) of three independent experiments.

To evaluate cell growth, $2 \times 10^{4}$ cells/well were seeded on 12 multi-well plastic microplates and the total cell number was estimated after the different incubation times. The cells were detached by mild trypsinization and counted in a Burker hemocytometer, and the data were expressed as the mean of three independent experiments \pm SE.

In order to evaluate the effect of NPs administration on cell proliferation, the $\mathrm{S}$ phase cells fraction was estimated $2 \mathrm{~h}, 24 \mathrm{~h}$ and $48 \mathrm{~h}$ after NPs exposure: cells grown on coverslips were pulse-labelled with $20 \mu \mathrm{M}$ bromodeoxyuridine (BrdU, Sigma) for $30 \mathrm{~min}$ at $37^{\circ} \mathrm{C}$, then fixed with $70 \%$ ethanol and treated for $20 \mathrm{~min}$ at room temperature in $2 \mathrm{~N} \mathrm{HCl}$, to denature DNA partially. After neutralization with $0.1 \mathrm{M}$ sodium tetraborate $(\mathrm{pH} 8.2)$ for 3 min, samples were washed in PBS, permeabilized for $15 \mathrm{~min}$ in PBS containing $0.1 \%$ bovine serum albumin and $0.05 \%$ Tween-20, and incubated for $1 \mathrm{~h}$ with a mouse monoclonal antibody recognizing BrdU (BD, Franklin Lakes, NJ, USA) diluted 1:20 in PBS. After two washings with PBS, samples were incubated for $1 \mathrm{~h}$ with an Alexafluor 594-conjugated antimouse secondary antibody (Molecular Probes, Invitrogen, Milan), diluted 1:200 in PBS. The cell samples were washed with PBS, stained for $5 \mathrm{~min}$ with $1 \mu \mathrm{g} / \mathrm{mL}$ Hoechst 33342 (Sigma) in PBS, and finally mounted in PBS:glycerol (1:1) to be observed and scored in fluorescence microscopy (see below). Data were expressed as the mean of three independent experiments \pm SE.

\section{Analysis of NPs intracellular distri- bution}

At each incubation time, HeLa cells were fixed for fluorescence microscopy with $4 \%$ (v/v) paraformaldehyde in PBS, pH 7.4, for 30 min at room temperature.

The samples were stained for DNA with Hoechst 33342 ( $1 \mu \mathrm{g} / \mathrm{mL}$ in PBS for $5 \mathrm{~min}$; Sigma), counterstained with $0.1 \%$ Trypan blue in PBS for $30 \mathrm{sec}$, rinsed in PBS, and mounted in a 1:1 mixture of glycerol:PBS (Calbiochem, Inalco, Milan, Italy): this allowed to visualize the intracellular presence of fluorescent NPs and to verify their possible intranuclear location. An Olympus BX51 microscope equipped with a 100W mercury lamp (Olympus Italia Srl, Milan, Italy) was used under the following conditions: $450-480 \mathrm{~nm}$ excitation filter (excf), $500 \mathrm{~nm}$ dichroic mirror (dm), and 515 $\mathrm{nm}$ barrier filter (bf), for FITC; $540 \mathrm{~nm}$ excf, $580 \mathrm{~nm} \mathrm{dm}$, and $620 \mathrm{~nm}$ bf, for Nile red; 330$385 \mathrm{~nm}$ excf, $400 \mathrm{~nm} \mathrm{dm}$, and $420 \mathrm{~nm}$ bf, for Hoechst 33342. Images were recorded with an QICAM Fast 1394 digital camera (QImaging, Surrey, BC, Canada) and processed using Image-Pro Plus 7.0 software (Media Cybernetics Inc., Rockville, MD, USA). For confocal laser scanning microscopy, a Leica TCS-SP system mounted on a Leica DMIRBE inverted microscope (Leica Microsystems Italia, Milan, Italy) was used; for fluorescence excitation, an Ar/Vis laser at $488 \mathrm{~nm}$ for FITC, a He/Ne laser at $543 \mathrm{~nm}$ for Nile red, and an $\mathrm{Ar} / \mathrm{UV}$ laser at $364 \mathrm{~nm}$ for Hoechst 33258 were used. Spaced $(0.5 \mu \mathrm{m})$ optical sections were recorded using a $63 \mathrm{x}$ oil immersion objective. Images were collected in the $1024 \times 1024$ pixel format, stored on a magnetic mass memory and processed by the Leica confocal software. For TEM, HeLa cells were fixed with $2.5 \%(\mathrm{v} / \mathrm{v})$ glutaraldehyde and $2 \%$ (v/v) paraformalde- 
hyde in $0.1 \mathrm{M}$ phosphate buffer, $\mathrm{pH} 7.4$, at $4^{\circ} \mathrm{C}$ for $2 \mathrm{~h}$, post-fixed with $1 \% \mathrm{OsO}_{4}$ and $1.5 \%$ potassium ferrocyanide at room temperature for $1 \mathrm{~h}$, dehydrated with acetone and embedded in Epon.

Ultrathin sections were weakly stained with uranyl acetate and observed in a Philips Morgagni transmission electron microscope (FEI Company Italia Srl, Milan, Italy) operating at $80 \mathrm{kV}$ and equipped with a Megaview II camera for digital image acquisition.

\section{Results}

\section{Characterization of NPs}

Liposomes (both uncoated and hyaluronic acid-coated) showed diameters around $230 \mathrm{~nm}$ (uncoated liposomes, $220 \pm 6 \mathrm{~nm}$; hyaluronic acid-coated liposomes, $245 \pm 3 \mathrm{~nm}, \mathrm{Pl}<0.1)$. As previously reported, ${ }^{4}$ liposome size increases with the addition of HA-DPPE conjugate. Zeta potential was negative for both formulations and was $-15.0 \pm 0.70 \mathrm{mV}$ for uncoated liposomes and more negative $(-43.0 \pm 1.11 \mathrm{mV})$ for hyaluronic acid-coated ones due to the presence of the carboxylic negative residues of HA on their surface. At TEM, they appeared as spherical vesicles of low electron density (Figure $1 \mathrm{a}, \mathrm{b}$ ).

Polymeric NPs were $104 \pm 25 \mathrm{~nm}$ in diameter (PI 0.1) and had a zeta potential of $-41 \pm 0.50$ $\mathrm{mV}$; at TEM, they appeared as spherical particles of moderate electron density (Figure 1c).

MSN were $100 \pm 23 \mathrm{~nm}$ in diameter with mesopores of about $3.5 \mathrm{~nm}$, and a zeta potential of $12.4 \pm 0.91 \mathrm{mV}$. At TEM, MSN appeared as spherical particles of moderate electron density, with well-ordered mesopores (Figure 1d).

\section{Cell viability}

The Trypan blue exclusion test showed that the percentage of dead cells in all NP-treated HeLa samples was lower than $1.5 \%$ at all incubation times, at no variance with control samples (Figure 2a).

The total number of cells was similar in control samples and in samples exposed to polymeric NPs and MSN at all times considered. Conversely, cell populations exposed to liposomes underwent significant modification in comparison to control samples; in detail, uncoated liposomes induced a decrease after $48 \mathrm{~h}$ incubation, while hyaluronic acid-coated liposomes induced a decrease after both $24 \mathrm{~h}$ and $48 \mathrm{~h}$ (Figure $2 \mathrm{~b}$ ).

The S-phase fraction did not significantly change after $2 \mathrm{~h}$ incubation with all NPs except from MSN, which showed a significant increase in BrdU incorporation. After $24 \mathrm{~h}$ incubation, no change was found in all samples while, after $48 \mathrm{~h}$ NPs incubation, BrdU incorporation significantly decreased in cells incubated with hyaluronic acid-coated liposomes and polymeric NPs (Figure 2c).

\section{Intracellular distribution of NPs}

\section{Liposomes}

Microscopic observations were similar for uncoated and hyaluronic acid-coated liposomes. Fluorescence microscopy showed that, after $2 \mathrm{~h}$ incubation, several liposomes had entered HeLa cells; they appeared as isolated NPs and never accumulated nor formed intracellular aggregates even after $48 \mathrm{~h}$ incubation (Figure $3 \mathrm{a}-\mathrm{c}$ ). Confocal microscopy confirmed the limited number of liposomes inside the cells, and demonstrated that they always localized in the peripheral region of the cell never entering the nucleus (Figure 4a). At TEM, liposomes were strongly electron dense due to the lipid staining by osmium tetroxide, and showed roundish shapes and shaggy profiles (Figure 5). Many liposomes - both singly and as small aggregates - were found adhering to the cell surface, while others occurred inside the cells, just below the plasma membrane or in the peripheral region of the cytoplasm (Figure 5 a,c). No internalization processes such as endocytosis or phagocytosis were observed, suggesting a direct translocation through the cell membrane. Liposomes never occurred in the inner part of the cytoplasm nor inside the cell nuclei. After cell internalization, many liposomes showed a loose filamentous content, and electron dense fine granular material occurred nearby in the cytosol (Figure 5b). Moreover, in the cells exposed to liposomes many lipid droplets were found: they frequently occurred close to the liposomes and contained the electron dense fine granular material, which appeared preferentially although not exclusively- distributed at their periphery (Figure 5b). After $2 \mathrm{~h}$, but especially after $24 \mathrm{~h}$ incubation, many lipid droplets accumulated in the outer cytoplasmic region, often budding from the cell surface until their extrusion in the extracellular milieu (Figure $5 \mathrm{c}, \mathrm{d}$ ). These lipid droplets were absent in the controls and in the cells treated with the other NP types. All HeLa cells incubated with liposomes contained large amounts of vesicular and membranous structures, although nuclei and cytoplasmic organelles did not show morphological alterations. This phenomenon was particularly evident after $24 \mathrm{~h}$ incubation and in cells treated with hyaluronic acid-coated liposomes. Consistent with the results on cell viability, no necrotic nor apoptotic figures were ever observed.
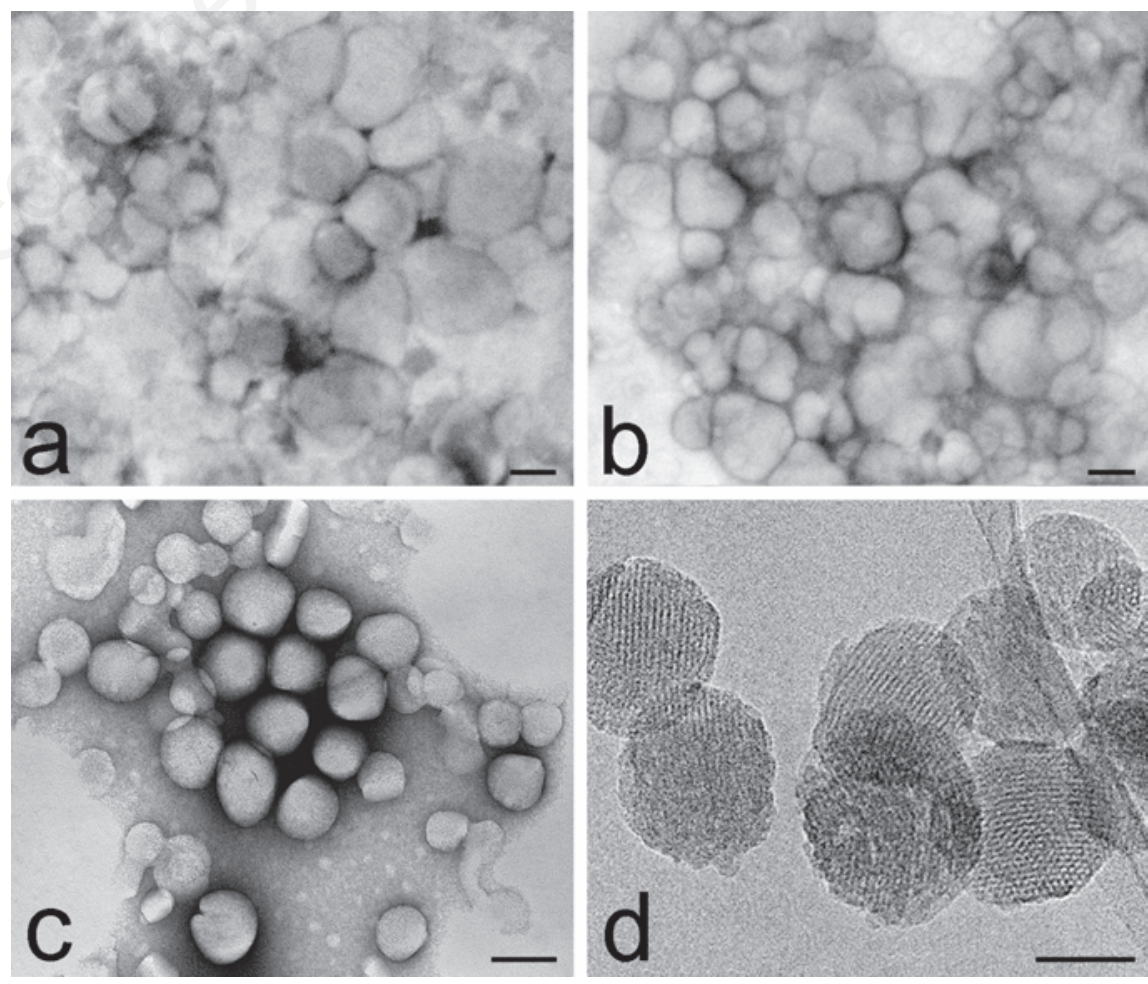

Figure 1. Transmission electron micrographs of uncoated liposomes (a), hyaluronic acidcoated liposomes (b), polymeric NPs (c) and MSN (d). Well-ordered mesopores are clearly visible in MSN. a-c). Negative staining. Scale bars: a-c) $100 \mathrm{~nm}$; $) 50 \mathrm{~nm}$. 


\section{Polymeric NPs}

Fluorescence microscopy revealed that polymeric NPs entered HeLa cells after $2 \mathrm{~h}$ incubation: they appeared as isolated NPs that progressively increased in number and accumulated in perinuclear areas, after $24 \mathrm{~h}$ (Figure 3 a'-c'). Confocal microscopy confirmed their cytoplasmic distribution and their absence in the cell nuclei (Figure 4b). At TEM, polymeric NPs showed a regular round shape and a moderate electron density (Figure 6). Single NPs were rarely found to adhere to the cell surface (Figure 6), and in the cytoplasm they appeared both inside membrane-bounded endosomes (Figure 6b) and free in the cytosol (Figure 6a); they never occurred inside the nucleus. After
$24 \mathrm{~h}$ incubation, a large number of roundish electron dense residual bodies accumulated in the perinuclear region of the cytoplasm (Figure 6e); this phenomenon did not occur in control cells or in samples treated with MSN or liposomes. Some polymeric NPs were surrounded by double membranes, as typical of autophagic figures (Figure $6 \mathrm{c,d}$ ). a

percentage of dead cells
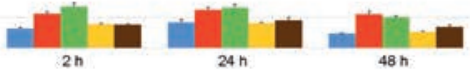

b

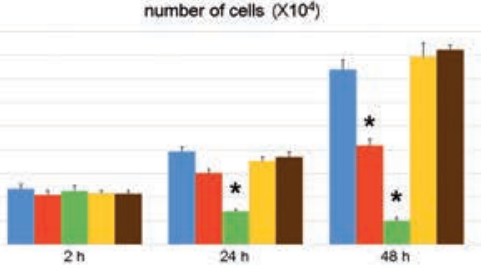

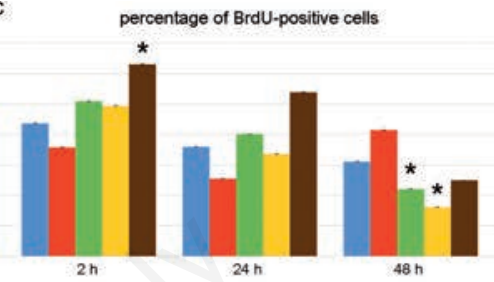

$\lim _{\substack{\lim \\: \rightarrow \infty n i m}}$

Figure 2. Effect of NP treatment on cell proliferation. a) Mean values \pm SE of dead cell percentage after 2,24 and $48 \mathrm{~h}$ incubation with the different NPs. b) Mean values \pm SE of cell number after 2, 24 and $48 \mathrm{~h}$ incubation with the different NPs. c) Mean values \pm SE of BrdU-positive cell percentage after 2, 24 and $48 \mathrm{~h}$ incubation with the NPs. In the histograms, values identified with asterisks are significantly different from the control (untreated) cells at the same incubation time. CTR, control; L, liposomes; LHA, hyaluronic acidcoated liposomes; Poly NPs, polymeric NPs; MSN, mesoporous silica nanoparticles.

Figure 3. Conventional fluorescence microscopy analysis of liposome (green fluorescence, ac), polymeric NP (red fluorescence, $a^{\prime}-c^{\prime}$ ) and MSN (green fluorescence, $\left.a^{\prime \prime}-b^{\prime \prime}\right)$ intracellular distribution after $\mathbf{2}$ h (a-a"), $24 \mathrm{~h}$ $\left(b-b^{\prime \prime}\right)$ and 48 h (c-c") incubation. All NPs are distributed in the whole cytoplasm, especially in the perinuclear region, but are apparently absent from nuclei. Polymeric NPs and MSN progressively accumulate inside the cells, whereas liposomes do not show evident accumulation at increasing treatment times. DNA is stained with Hoechst 33342 (blue fluorescence); in a-c and $a^{\prime \prime}-b^{\prime \prime}$ the cytoplasm is counterstained with Trypan blue (red fluorescence). Scale bars: $20 \mu \mathrm{m}$.
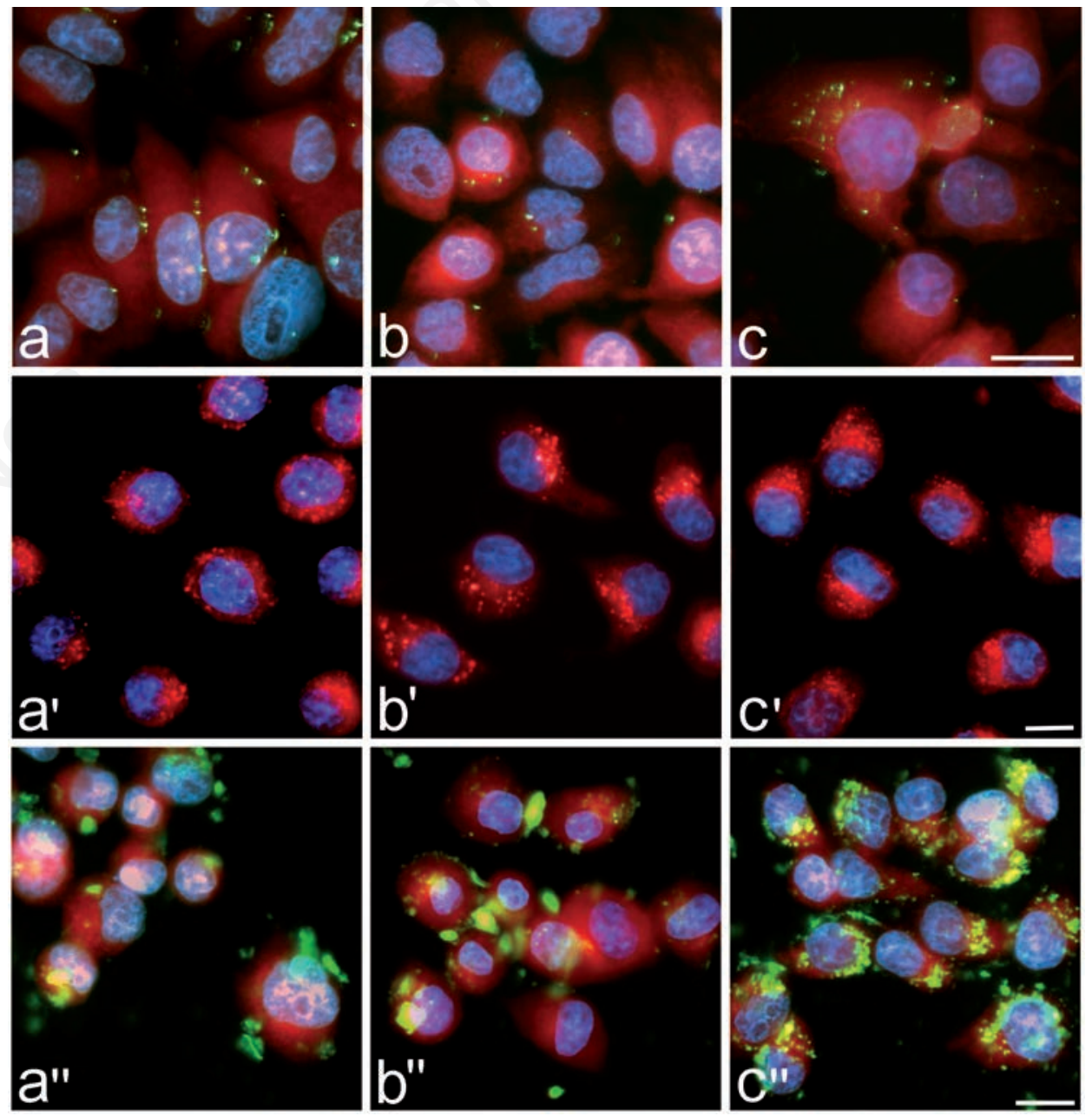
Figure 4. Confocal $500 \mathrm{~nm}$ spaced optical sections of HeLa cells after $24 \mathrm{~h}$ incubation with liposomes (green fluorescence, a), polymeric NPs (red fluorescence, b) and MSN (green fluorescence, c). Al the NPs are distributed in the cytoplasm but are absent from the nucleus; note the peripheral location of liposomes. DNA is stained with Hoechst 33342 (blue fluorescence). In a and $\mathrm{c}$ the cytoplasm is counterstained with Trypan blue (red fluorescence); in b the red fluorescent signal of polymeric NPs has been merged with the brighfield image. Scale bars: $20 \mu \mathrm{m}$.

Figure 5. Transmission electron microscopy analysis of liposomes intracellular distribution after 2 $h(a, b)$ and $24 h$ (c, d) incubation. a) Several liposomes enter the cell apparently without endocytotic process and occur free in the cytoplasm. Note their loose filamentous periphery. b) Electron dense fine granular material (arrow) occurs in the cytosol in close proximity to liposomes and lipid droplets $(\mathrm{L})$. Granular material appears distributed also at the periphery (arrowheads) of the lipid droplets (L). c) After $24 \mathrm{~h}$ incubation, while liposome uptake continue (arrow), nearly all lipid droplets (L) contain electron dense granular material and some of them bud from the cell surface (arrowheads). d) Detail of a peripheral cellular region: two lipid droplets $(\mathrm{L})$ containing granular material approach the cell surface and one is extruded (arrowhead). Cell organelles appear hardly recognizable. Scale bars: $500 \mathrm{~nm}$.
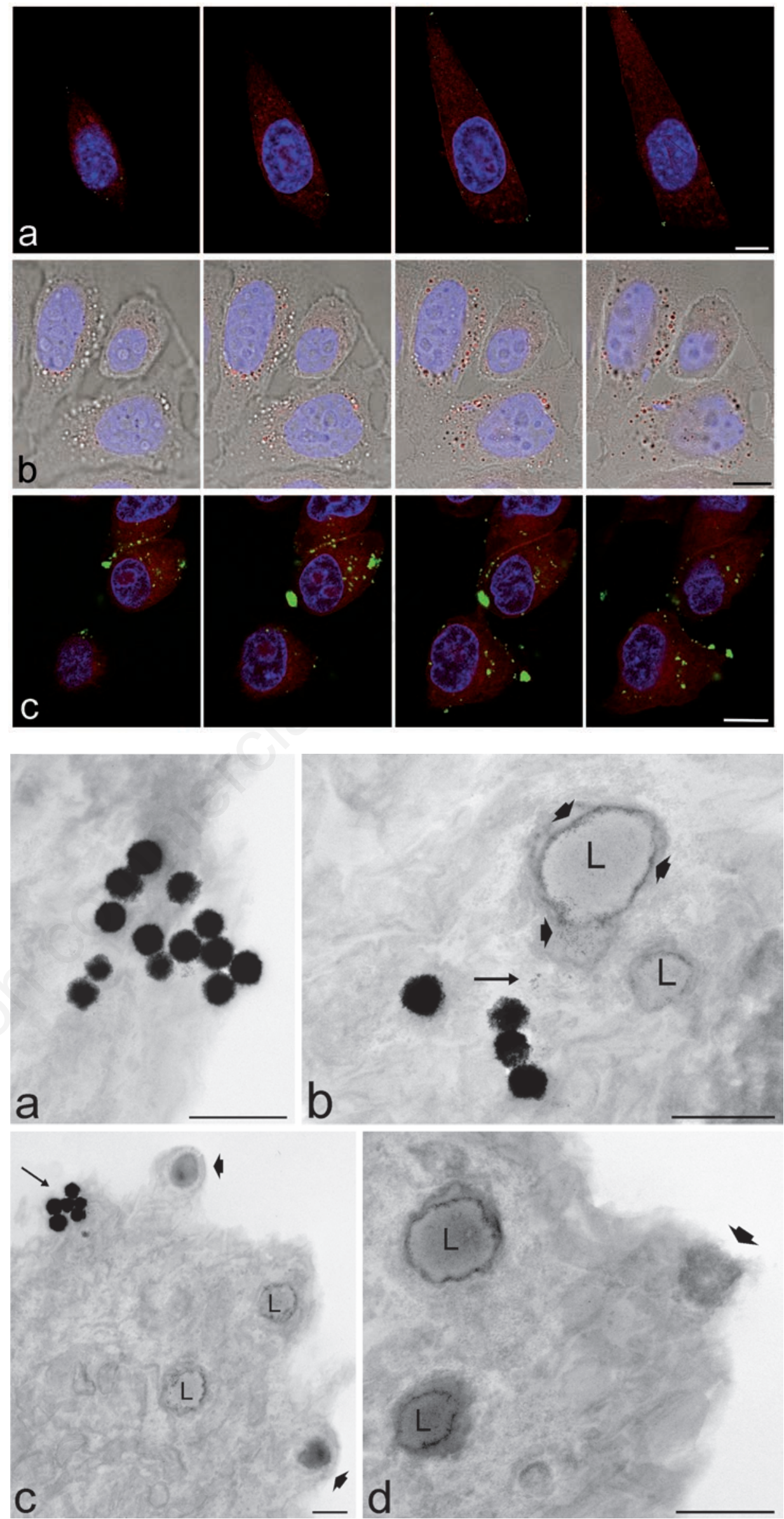
No contact between polymeric NPs and cytoplasmic organelles, nor indication of cell alteration or damage were ever observed at any incubation time.

\section{MSN}

Observation at conventional and confocal fluorescence microscopy revealed that, after $2 \mathrm{~h}$ incubation, many MSN were internalized by HeLa cells, and it was evident that their amount progressively increased up to $24 \mathrm{~h}$
(Figure 3 a"-c"). MSN often occurred as clusters both at the cell surface and inside the cytoplasm; after $24 \mathrm{~h}$ incubation most of MSN were located around (but never inside) the nucleus (Figure 4c). At TEM the MSN were roundish and highly electron dense (Figure 7). According to the observations in fluorescence microscopy, many MSN were found to adhere to the cell surface, frequently as large aggregates (Figure 7a). Single or few MSN were internalized by endocytosis (Figure 7c), while the large clusters entered the cell via phagocytosis (Figure 7b). In the cytoplasm, MSN were always found inside vacuoles of various sizes that were ubiquitously distributed in the cytoplasm (sometimes very close to the nuclear envelope), but they were never found inside cell nuclei (Figure $7 \mathrm{~d}, \mathrm{e}$ ). After $24 \mathrm{~h}$ incubation, MSN were observed inside large vacuoles (probably secondary lysosomes or residual bodies) containing heterogeneous material (Figure 7f). MSN did not contact any

Figure 6. Transmission electron microscopy analysis of polymeric NPs intracellular distribution after $2 \mathrm{~h} \mathrm{(a-d)}$ and $24 \mathrm{~h} \mathrm{(e)} \mathrm{incubation.} \mathrm{a)}$ Two polymeric NPs occurs at the cell periphery: one adhering to the cell surface (arrowhead), the other freely distributed in the cytosol (arrow). b) A polymeric NP is enclosed in an endosome (arrow). Polymeric NPs are partially (c) and completely (d) enclosed by autophagic dual membranes (arrows). e) After $24 \mathrm{~h}$ incubation, the cytoplasm contains numerous small and strongly electron dense residual bodies (arrowheads). G, glycogen; L, lipid droplet; $N$, nucleus Scale bars: $200 \mathrm{~nm}$.

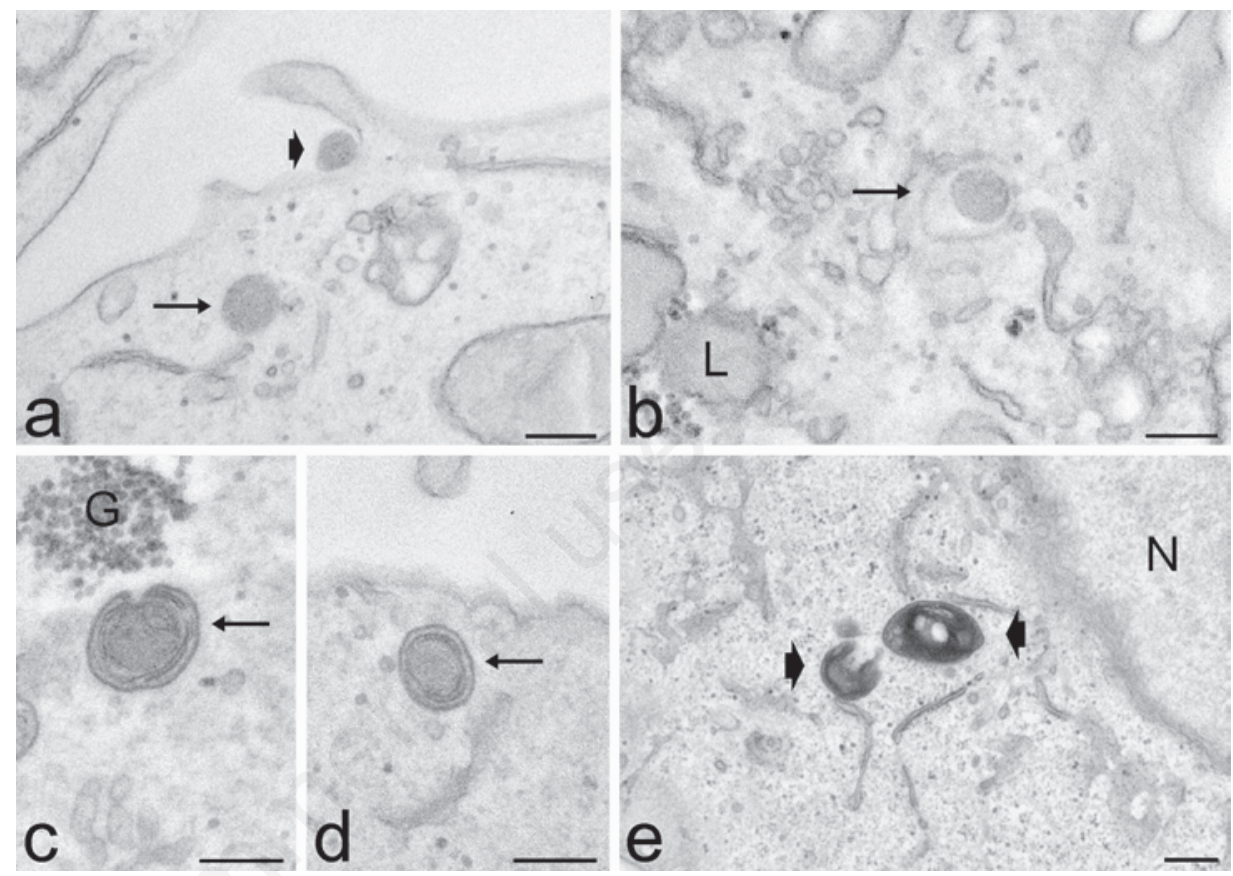

Figure 7. Transmission electron microscopy analysis of MSN intracellular distribution after $\mathbf{2}$ h (a-d) and $24 \mathrm{~h}(\mathrm{e}, \mathrm{f})$ incubation. a) Large aggregates of MSN occurs at the cell surface (asterisks). Small clusters of MSN are visible inside the cytoplasm, even inside nuclear invaginations (arrows). The arrowhead indicates the detail showed in b. b) A MSN cluster is internalised via phagocytosis by the extrusion of pseudopodia (arrows). c) Small clusters of MSN enter the cells by endocytosis (arrows). d-e) Vacuoles containing MSN (arrows) are ubiquitously distributed in the cytoplasm, sometimes very close to the nucleus (N). f) MSN occur in large vacuoles containing heterogeneous material. L, lipid droplets; N, nucleus. Scale bars: a) $5 \mu \mathrm{m}$; b-f) $500 \mathrm{~nm}$.
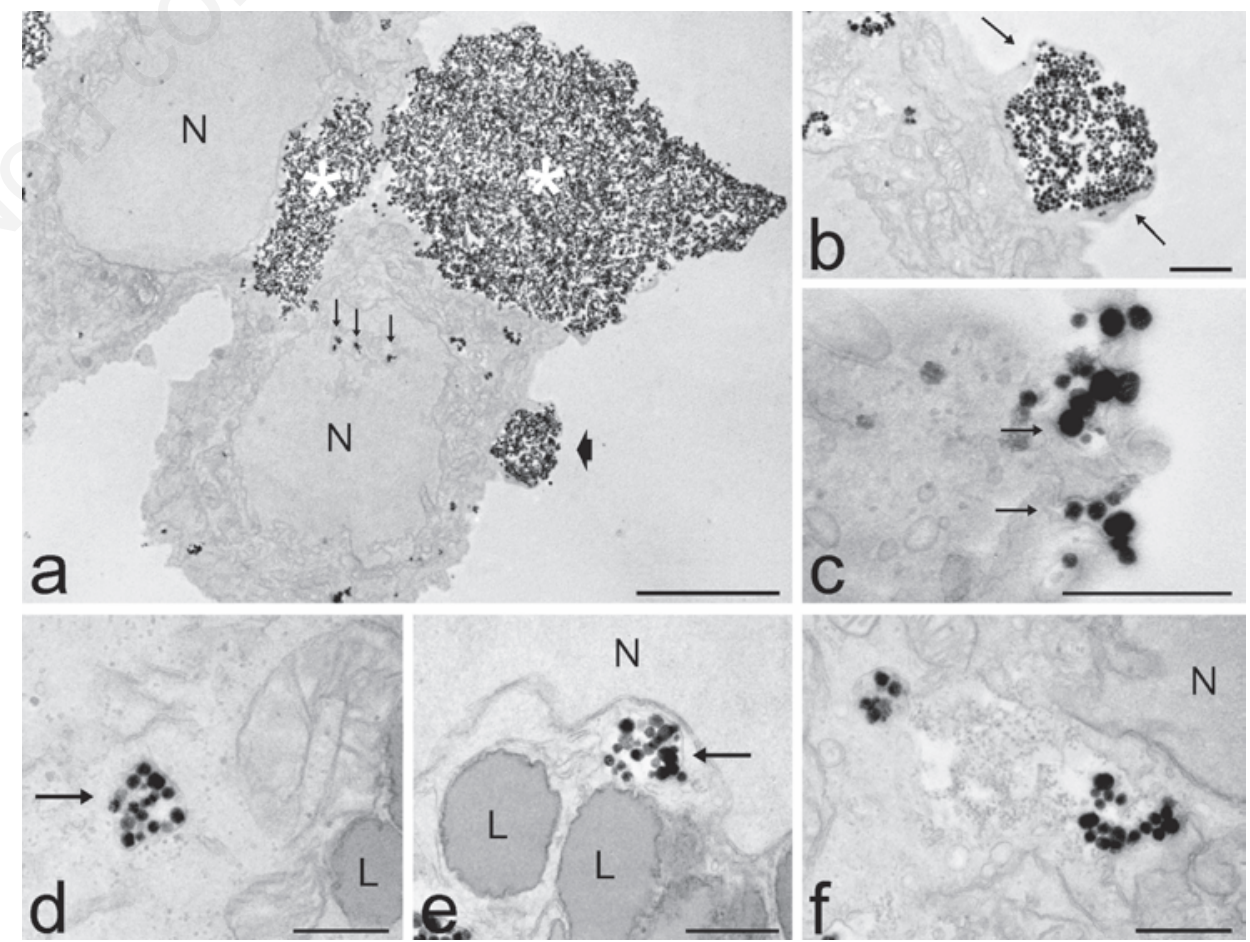
particular organelle, and there was never sign of subcellular alteration or damage at any incubation time.

\section{Discussion}

Biocompatibility and non-toxicity are essential prerequisites for nanocarriers to avoid adverse effects in the patient's organism, and are especially important when NPs are aimed at delivering therapeutic agents to restore the normal physiological functions in diseased cells which are to be preserved: this is the case with highly differentiated non-cycling cells such as myofibres and neurons.

In our experimental model, cell death was apparently unaffected by the exposure to the various NPs, consistently with previously published data by our group ${ }^{4,14}$ and others. ${ }^{25}$ However, hyaluronic acid-coated liposomes were found to significantly reduce cell population after both $24 \mathrm{~h}$ and $48 \mathrm{~h}$, while uncoated liposomes induced a decrease after $48 \mathrm{~h}$ only. The slowdown of cell proliferation demonstrated after $48 \mathrm{~h}$ incubation with hyaluronic acidcoated liposomes partially explains such a cell number reduction, but it is likely that also cell death contributes to the population decline. This is only apparently in contrast with the results obtained by the Trypan blue exclusion test; in fact, it should be considered that dead cells, after detaching from the substrate, may undergo rapid degradation thus becoming undetectable: this may cause their underestimation especially at long incubation times.

Our experimental model seems therefore more sensitive to the treatment with liposomes in comparison to other previously investigated cell lines. ${ }^{4}$ The stronger effect of hyaluronic-acid-coated liposomes is probably due to the capability of hyaluronic acid to increase the uptake efficiency by cells bearing CD44 receptors ${ }^{24,27}$ as HeLa cells, ${ }^{28}$ although the rapid disaggregation of these NPs does not allow to observe any difference in their intracellular accumulation. This observation confirms and extends previous data demonstrating that NP biocompatibility may depend -at least in part- on the cell type..$^{29}$

Polymeric NPs were found to slow down cell proliferation after $48 \mathrm{~h}$ incubation, although the total cell number remained unaffected. This phenomenon has been already observed in cultured epithelial cells incubated with polymeric NPs for 1-3 days ${ }^{30}$ and may be due to the intracellular overload of NPs and/or their remnants after long incubation times. The longterm effect of polymeric NP internalization certainly deserves further investigation since a significant reduction in cell proliferation may represent a predictive sign of cell death.
Conversely, cell proliferation was increased after brief ( $2 \mathrm{~h}$ ) exposure to MSN: this is consistent with previous observations by Christen et $a l^{31}$ and our group (unpublished results), and could be related to the silica-NP-induced activation of MAPK signaling and the downregulation of $p 53$, which in turn inhibit apoptosis and induce cell proliferation.

Fluorescence microscopy demonstrated that cell uptake is quite rapid and efficient for all the NPs tested, although evident differences have been found in their intracellular distribution. TEM allowed monitoring the fine structural relationships between NPs and cell components, clarifying the uptake mechanisms and the intracellular fate of internalized NPs.

MSN enter cells in large amounts via both endocytosis and phagocytosis; once internalized, they always occur inside vacuoles, thus remaining segregated from the cytosol and cytoplasmic organelles. MSN were never found free in the cytosol and this suggests they are unable to escape endosomes (contrary to other NP types ${ }^{32-35}$ ). MSN do follow the intracellular lytic pathway, as suggested by the presence of residual bodies containing numerous NPs and heterogeneous cellular remnants (this was especially clear after $24 \mathrm{~h}$ incubation). Such an intracellular behavior must be taken into consideration when using MSN for drug delivery in vivo: in this case, the therapeutic agents to be targeted by MSN should be carefully selected to be able to cope with the lytic action of lysosomal enzymes, and to be capable of passing through the vacuole membrane before diffusing in the cytoplasm. Interestingly, MSN did not show any sign of morphological degradation even inside residual bodies; this demonstrates their long intracellular persistence and points to MSN as especially suitable nanovectors for sustained drug release. In addition, since MSN accumulate very close to the nuclear envelope, they could profitably be used to release drugs directed to nuclear targets. It is worth noting that, despite the large number of internalized MSN, the cells did not show any sign of organelle alteration or damage after $24 \mathrm{~h}$ exposure. Consistently, no ultrastructural alteration was found in a murine myoblast cell line after 7 days from MSN exposure, ${ }^{36}$ thus confirming the good biocompatibility of these nanovectors. The same study ${ }^{36}$ demonstrated that MSN uptake enhances differentiation into myotubes, opening interesting perspectives for their use in low renewing differentiated tissues.

Polymeric NPs enter the cell individually probably via endocytosis, and diffuse in the whole cytoplasm, accumulating in perinuclear position after long incubation times. They occur in the cytoplasm either inside endosomes or free in the cytosol, thus suggesting that these NPs can escape endosomes, as pre- viously observed for other polymeric NPs..$^{21,33,35}$ Nevertheless, many polymeric NPs re-enter the lytic pathway due to the autophagic process, thus undergoing enzymatic degradation and giving rise to the numerous residual bodies observed after $24 \mathrm{~h}$ incubation. TEM observations therefore suggest that many of the fluorescing spots visible in the cytoplasm at fluorescence microscopy after long incubation times might correspond to the remnants of polymeric NPs inside residual bodies. The short intracellular permanence of polymeric NPs suggests that they may be especially suitable for rapid drug release. According to previous observations, ${ }^{37,38}$ polymeric NPs have never been found inside cell nuclei.

The uncoated and hyaluronic acid-coated liposomes show a similar intracellular distribution pattern: they enter massively the cell, probably mainly by fusion with the plasma membrane $^{39,40}$ (although a receptor-mediated internalization cannot be excluded), and undergo rapid degradation in the peripheral region of the cytoplasm (no liposomes have ever been found in the inner part of the cytoplasm or in the nucleus). The presence of granular electron dense material in close proximity of liposomes and inside the adjacent lipid droplets suggests that liposome components are released and migrate into the cytosol to accumulate, probably due to chemical affinity, into the lipid deposits. At present, we cannot establish the reason for liposome degradation, which could be due to either intracellular lipases or intrinsic characteristics of the nanocarriers. In any case, this phenomenon should be taken into consideration when using liposomes as drug carriers; in fact, their rapid degradation could be exploited to allow a rapid and massive release of the therapeutic agent. The accumulation and extrusion of lipid droplets, observed in HeLa cells only after liposome internalization, likely represent different steps of the compartmentalization and elimination process of exogenous material due to excessive NP uptake. Accordingly, signs of cytological alteration are evident, especially after internalization of liposomes coated with hyaluronic acid, which increases uptake efficiency ${ }^{24,27,28}$ However, no necrotic or apoptotic cells were found in the slides incubated with liposomes, probably due to detachment from the substrate and/or degradation of dead cells. It should be underlined that the observation at fluorescence microscopy did not reveal any significant alteration in liposome-treated cells and only the high resolution of TEM demonstrated the actual occurrence of subcellular damages.

Interestingly, no one of the tested nanocarriers was found to enter the nucleus, even after long incubation times, thus demonstrating that they are unable not only to pass 
through the nuclear pores but also to be entrapped by the nuclear envelope when it reforms after each mitotic cycle. ${ }^{25,41}$ Entering cell nuclei might be considered as an advantage for drug-loaded NPs to reach intranuclear targets; however, it is worth noting that this may indubitably represent a risk because of the possible interactions between NPs per se and nucleic acids and/or nuclear factors, which could unpredictably alter cell function, irrespective of the drug action. In addition, it is well known that NP-mediated delivery of drugs or oligonucleotides to nuclear targets does not require that the nanocarrier enters the nucleus, ${ }^{42,43}$ but essentially depends on the chemical nature of the therapeutic agents.

The biocompatible nanocarriers designed for drug delivery that have been tested in this study are ultimately intended for in vivo administration and further investigations on the complex interactions with the whole organism are mandatory to plan their therapeutic utilization. However, a nanocarrierbased therapeutic strategy cannot disregard basic knowledge and this study provides essential information on the structural and functional interactions of NPs with the cell components, further proving that microscopy techniques (and especially TEM) are irreplaceable in the attempt to describe the biological behavior of nanovectors.

\section{References}

1. Wicki A, Witzigmann D, Balasubramanian V, Huwyler J. Nanomedicine in cancer therapy: challenges, opportunities, and clinical applications. J Control Rel 2015; 200:138-57.

2. Yohan D, Chithrani BD. Applications of nanoparticles in nanomedicine. J Biomed Nanotechnol 2014;10:2371-92.

3. Estanqueiro M, Amaral MH, Conceição J, Sousa Lobo JM. Nanotechnological carriers for cancer chemotherapy: the state of the art. Colloids Surf B Biointerfaces 2015;126:631-48.

4. Arpicco S, Lerda C, Dalla Pozza E, Costanzo C, Tsapis N, Stella B, et al. Hyaluronic acid-coated liposomes for active targeting of gemcitabine. Eur $\mathrm{J}$ Pharm Biopharm 2013;85:373-80.

5. Pedrini I, Gazzano E, Chegaev K, Rolando B, Marengo A, Kopecka J, et al. Liposomal nitrooxy-doxorubicin: one step over Caelyx $^{\circledR}$ in drug-resistant human cancer cells. Mol Pharm 2014;11:3068-79.

6. Arpicco S, Canevari S, Ceruti M, Galmozzi E, Rocco F, Cattel L. Synthesis, characterization and transfection activity of new saturated and unsaturated cationic lipids. Il
Farmaco 2004;59:869-78.

7. De Rosa G, De Stefano D, Laguardia V, Arpicco S, Simeon V, Carnuccio R, et al. Novel cationic liposome formulation for the delivery of an oligonucleotide decoy to NF- B into activated macrophages. Eur J Pharm Biopharm 2008;70:7-18.

8. Taetz S, Bochot A, Surace C, Arpicco S, Renoir JM, Schaefer UF, et al. Hyaluronic acid-modified DOTAP/DOPE liposomes for the targeted delivery of antitelomerase siRNA to CD44-expressing lung cancer cells. Oligonucleotides 2009;19:103-15.

9. Surace C, Arpicco S, Dufay-Wojcicki A, Marsaud V, Bouclier C, Clay D, et al. Lipoplexes targeting the CD44 hyaluronic acid receptor for efficient transfection of breast cancer cells. Mol Pharm 2009;6: 1062-73.

10. Nascimento TL, Hillaireau H, Noiray M, Bourgaux V, Arpicco S, Pehau-Arnaudet G, et al. Supramolecular organization and siRNA binding of hyaluronic acid-coated lipoplexes for targeted delivery to the CD44 receptor. Langmuir 2015;31:11186-94.

11. Grottkau BE, Cai X, Wang J, Yang X, Lin Y. Polymeric nanoparticles for a drug delivery system. Curr Drug Metab 2013;14:840-6.

12. Stella B, Arpicco S, Peracchia MT, Desmaële D, Hoebeke J, Renoir JM, et al. Design of folic acid-conjugated nanoparticles for drug targeting. J Pharm Sci 2000;89:1452-64.

13. Stella B, Arpicco S, Rocco F, Marsaud V, Renoir JM, Cattel L, et al. Encapsulation of gemcitabine lipophilic derivatives into polycyanoacrylate nanospheres and nanocapsules. Int J Pharm 2007;344:71-7.

14. Stella B, Marsaud V, Arpicco S, Géraud G, Cattel L, Couvreur P, et al. Biological characterization of folic acid-conjugated poly(H2NPEGCA-co-HDCA) nanoparticles in cellular models. J Drug Target 2007;15: 146-53.

15. Lince F, Bolognesi S, Stella B, Marchisio DL, Dosio F. Preparation of polymer nanoparticles loaded with doxorubicin for controlled drug delivery. Chem Eng Res Des 2011;89:2410-9.

16. Chen Y, Chen H, Shi J. Drug delivery/imaging multifunctionality of mesoporous silica-based composite nanostructures. Expert Opin Drug Deliv 2014;11:917-30.

17. Sapino S, Ugazio E, Gastaldi L, Miletto I, Berlier G, Zonari D, et al. Mesoporous silica as topical nanocarriers for quercetin: characterization and in vitro studies. Eur J Pharm Biopharm 2015;89:116-25.

18. Peng J, He X, Wang K, Tan W, Li H, Xing X, et al. An antisense oligonucleotide carrier based on amino silica nanoparticles for antisense inhibition of cancer cells. Nanomedicine 2006;2:113-20.
19. Panyam J, Zhou WZ, Prabha S, Sahoo SK, Labhasetwar V. Rapid endolysosomal escape of poly(DL-lactide-coglycolide) nanoparticles: implications for drug and gene delivery. FASEB J 2002;16:1217-26.

20. Watson P, Jones AT, Stephens DJ. Intracellular trafficking pathways and drug delivery: fluorescence imaging of living and fixed cells. Adv Drug Deliv Rev 2005; 57:43-61.

21. Malatesta M, Pellicciari C, Cisterna B, Costanzo M, Galimberti V, Biggiogera M, et al. Tracing nanoparticles and photosensitizing molecules at transmission electron microscopy by diaminobenzidine photooxidation. Micron 2014;59C:44-51.

22. Lince F, Bolognesi S, Marchisio DL, Stella B, Dosio F, Barresi A, Cattel L. Preparation of poly(MePEGCA-co-HDCA) nanoparticles with confined impinging jets reactor: experimental and modeling study. J Pharm Sci 2011b;100:2391-405.

23. Fessi H, Puisieux F, Devissaguet JPh, Ammoury N, Benita S. Nanocapsule formation by interfacial polymer deposition following solvent displacement. Int J Pharm 1989;55:R1-R4.

24. Yu M, Jambhrunkar S, Thorn P, Chen J, Gu W, Yu C. Hyaluronic acid modified mesoporous silica nanoparticles for target drug delivery to CD44-overexpressing cancer cells. Nanoscale 2013;5:178-83.

25. Guan M, Zhu Q, Liu Y, Bei Y-Y, Gu Z-L, Zhang X-N, et al. Uptake and transport of a novel anticancer drug-delivery system: lactosyl-norcantharidin-associated $\mathrm{N}$ trimethyl chitosan nanoparticles across intestinal Caco-2 cell monolayers. Int $\mathrm{J}$ Nanomedicine 2012;7:1921-30.

26. Hahn AT, Jones JT, Meyer T. Quantitative analysis of cell cycle phase durations and PC12 differentiation using fluorescent biosensors. Cell Cycle 2009;8:1044-52.

27. Li J, Hu Y, Yang J, Wei P, Sun W, Shen M, et al. Hyaluronic acid-modified $\mathrm{Fe}_{3} \mathrm{O}_{4} @ \mathrm{Au}$ core/shell nanostars for multimodal imaging and photothermal therapy of tumors. Biomaterials 2015;38:10-21.

28. Bruno S, Fabbi M, Tiso M, Santamaria B, Ghiotto F, Saverino D, et al. Cell activation via CD44 occurs in advanced stages of squamous cell carcinogenesis. Carcinogenesis 2000;21:893-900.

29. Chang JS, Chang KL, Hwang DF, Kong ZL. In vitro cytotoxicitiy of silica nanoparticles at high concentrations strongly depends on the metabolic activity type of the cell line. Environ Sci Technol 2007;41:2064-8.

30. Hussien R, Rihn BH, Eidi H, Ronzani C, Joubert 0, Ferrari L, et al. Unique growth pattern of human mammary epithelial cells induced by polymeric nanoparticles. Physiol Rep 2013;1:e00027. 
31. Christen V, Camenzind M, Fent K. Silica nanoparticles induce endoplasmic reticulum stress response, oxidative stress and activate the mitogen-activated protein kinase (MAPK) signaling pathway. Toxicology Reports 2014;1:1143-51.

32. Serda RE, Mack A, van de Ven AL, Ferrati S, Dunner K Jr, Godin B, et al. Logic-embedded vectors for intracellular partitioning, endosomal escape, and exocytosis of nanoparticles. Small 2010;6:2691-700.

33. Varkouhi AK, Scholte M, Storm G, Haisma HJ. Endosomal escape pathways for delivery of biologicals. J Control Release 2011; 151:220-8.

34. Zaki NM, Nasti A, Tirelli N. Nanocarriers for cytoplasmic delivery: cellular uptake and intracellular fate of chitosan and hyaluronic acid-coated chitosan nanoparticles in a phagocytic cell model. Macromol Biosci 2011;11:1747-60.

35. Malatesta M, Giagnacovo M, Costanzo M, Conti B, Genta I, Dorati R, et al.
Diaminobenzidine photoconversion is a suitable tool for tracking the intracellular location of fluorescently labelled nanoparticles at transmission electron microscopy. Eur J Histochem 2012;56:e20.

36. Poussard S, Decossas M, Le Bihan 0, Mornet S, Naudin G, Lambert 0 . Internalization and fate of silica nanoparticles in $\mathrm{C} 2 \mathrm{C} 12$ skeletal muscle cells: evidence of a beneficial effect on myoblast fusion. Int $\mathbf{J}$ Nanomedicine 2015;10:1479-92.

37. Kim HR, Gil S, Andrieux K, Nicolas V, Appel M, Chacun H, et al. Low-density lipoprotein receptor-mediated endocytosis of PEGylated nanoparticles in rat brain endothelial cells. Cell Mol Life Sci 2007;64: 356-64.

38. Brambilla D, Nicolas J, Le Droumaguet B, Andrieux K, Marsaud V, Couraud PO, et al. Design of fluorescently tagged poly(alkyl cyanoacrylate) nanoparticles for human brain endothelial cell imaging. Chem Commun (Camb) 2010;46:2602-4.

39. Verma A, Stellacci F. Effect of surface prop- erties on nanoparticle-cell interactions. Small 2010;6:12-21.

40. Nazarenus M, Zhang Q, Soliman MG, del Pino P, Pelaz B, Carregal-Romero S, et al. In vitro interaction of colloidal nanoparticles with mammalian cells: What have we learned thus far? Beilstein J Nanotechnol 2014;5:1477-90.

41. Malatesta M, Grecchi S, Chiesa E, Cisterna B, Costanzo M, Zancanaro C. Internalized chitosan nanoparticles persist for long time in cultured cells. Eur J Histochem 2015;59:2492.

42. Zhao F, Zhao Y, Liu Y, Chang X, Chen C, Zhao Y. Cellular uptake, intracellular trafficking, and cytotoxicity of nanomaterials. Small 2011;7:1322-37.

43. Yameen B, Choi WI, Vilos C, Swami A, Shi J, Farokhzad OC. Insight into nanoparticle cellular uptake and intracellular targeting. J Control Rel 2014;190:485-99. 